\title{
Voltage Source Equipment for the Grid Fault Testing and Analysis of Total Harmonic Distortion According to PWM Methods
}

\author{
Jin-Su Gwon ${ }^{*}$, Chun-Sung Kim, Dae-Wook Kang ${ }^{*}$, Jung-Woo Park ${ }^{*}$, and Sungshin Kim ${ }^{\dagger}$ \\ *Power Conversion and Control Research Center, Korea Electrotechnology Research Institute, Changwon, Korea \\ ${ }^{\dagger}$ Department of Electrical Engineering, Pusan National University, Pusan, Korea
}

\begin{abstract}
Renewable energy is being spotlighted as the electric power generating source for the next generation. Due to an increase in renewable energy systems in the grid system, their impact on the grid has become non-negligible. Thus, many countries in the world, including Europe, present their own grid codes for grid power conversion devices. In order to experiment with these grid codes, grid fault test equipment is required. This paper proposes both equipment and a control method, which are constructed with a 7-level cascaded H-bridge converter, that are capable of generating various grid faults. In addition, the Pulse Width Modulation (PWM) method for multilevel converters is compared and analyzed. The proposed structure, the control method, and the PWM method are verified through simulation and experimental results.
\end{abstract}

Key words: Carrier-based space vector PWM, Cascaded multilevel converter, Voltage source equipment, Weak grid controller

\section{INTRODUCTION}

Recently, renewable energy which does not destroy the environment has been spotlighted as the electric power generation source for the next generation. Representative renewable energy sources are wind, solar, tidal, wave, etc. In particular, wind power has been rapidly growing. Approximately $35 \mathrm{GW}$ of additional wind power systems were installed around the world in 2013. At the end of 2013, the cumulatively installed wind capacity reached almost $320 \mathrm{GW}$. With the annually-installed capacity in 2013 the order in terms of how often the installations occur is: Asia, Europe and North America [1], [2].

Due to the increase in renewable energy systems in the grid systems, the impact on grids has been getting to be non-negligible. Thus, many countries in the world, including Europe, present their own grid codes for grid power conversion devices. The main focus of these grid codes is the ability to

Manuscript received Jun. 2, 2014; accepted Sep. 29, 2014

Recommended for publication by Associate Editor Kyo-Beum Lee.

${ }^{\dagger}$ Corresponding Author: sskim@pusan.ac.kr

Tel: +82-51-510-2374, Pusan National University

*Power Conversion and Control Research Center, Korea

Electrotechnology Research Institute, Korea

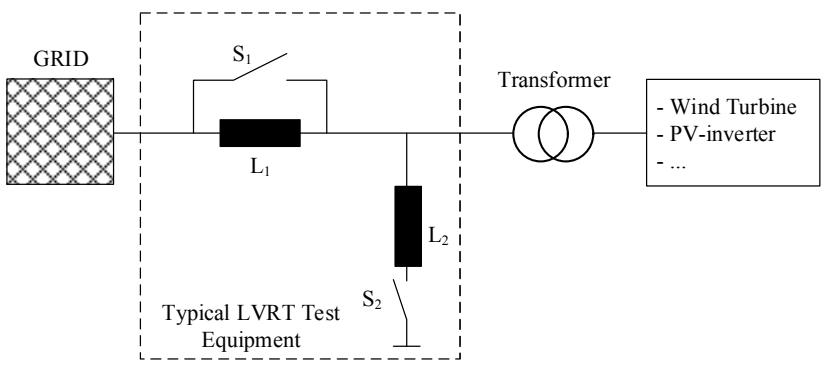

Fig. 1. Typical LVRT Test Equipment.

achieve Low-Voltage Ride-Through (LVRT) [2], [3]. In order to verify the LVRT capability required for these grid codes, LVRT test equipment is required. Generally, the well-known LVRT test equipment on an industrial scale is composed of inductors and bypass switches, as shown in Fig. 1 [4].

This LVRT test equipment is limited in terms of both frequency range and dynamics [5], [6]. The National Renewable Energy Laboratory (NREL) proposed the Controllable Grid Interface (CGI) in order to make various grid faults. This simulator is configured with NPC three-level converters in parallel for the large capacity type. With this simulator it is easy to expand the capacity because each inverter is composed of modules in parallel [5]. However, the total cost escalates due to the fact that the number of switching 


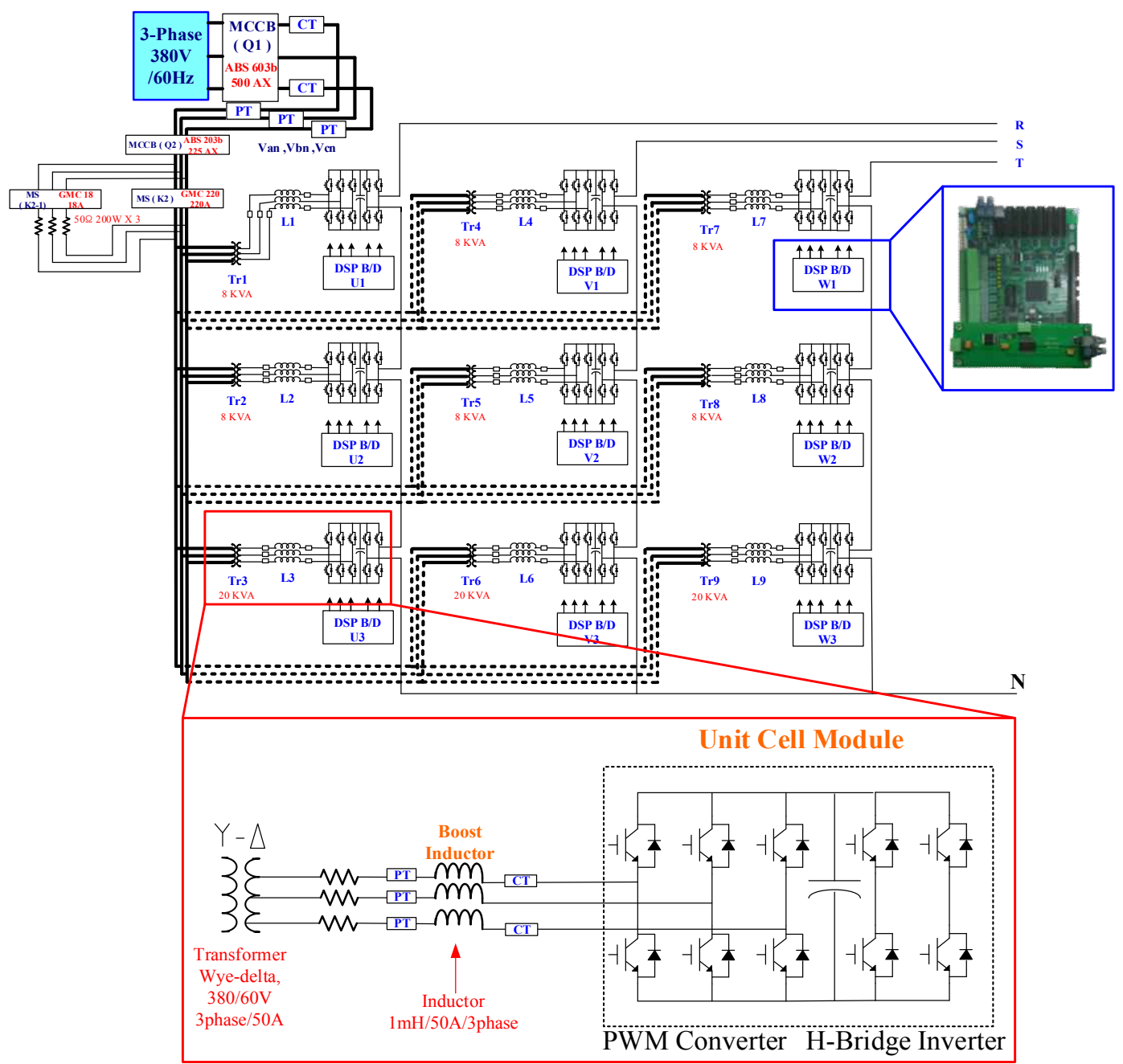

Fig. 2. Structure of Voltage Source Equipment using 7-level Cascaded H-bridge Converter.

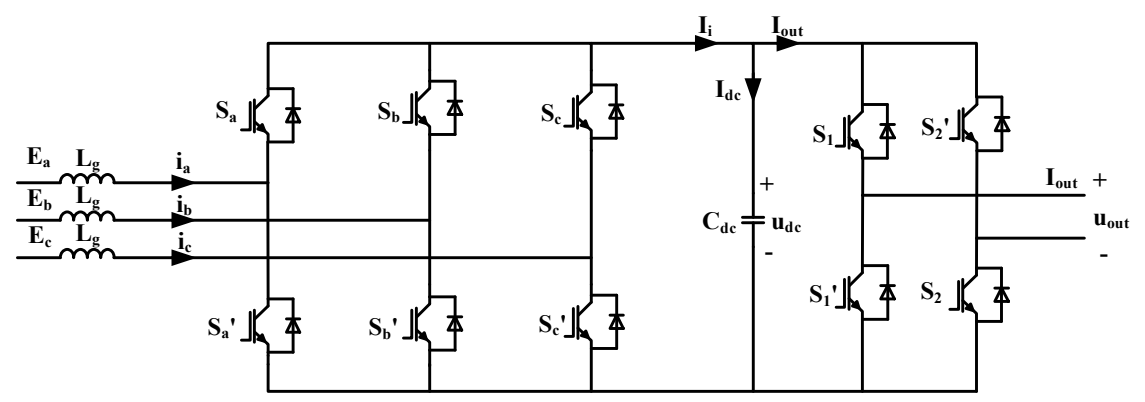

Fig. 3. Detailed model of H-Bridge unit cell module.

elements increases exponentially. In addition, the balancing controller of the dc-link voltage is needed. In reference [7], a three-phase H-Bridge inverter for the grid simulator was proposed. This method has advantages, such as a relatively simple hardware configuration and rapid response. However, it is difficult to

expand the capacity, since this requires a large output filter, while each phase requires a non-linear controller. Therefore, this study proposes Voltage Source Equipment (VSE) by using 7-level cascaded H-Bridge converters as shown in Fig. 2. It can generate various grid faults with a 3-phase independent controller. The cascaded H-Bridge converter is easy to expand for equipment that is capable of testing large capacity LVRTs since it can extend the capacity by combining a small amount of the capacity of the sub-module (SM) in series. Fig. 3 shows a detailed model of the H-Bridge unit cell module. The multilevel H-Bridge converter needs an independent and insulated dc power supply. Therefore, the unit cell module is composed of a PWM converter in order to generate the isolated dc source voltage and an H-bridge inverter in order to generate the output voltage. Additional dc-link balancing controllers are not required because the inverter is combined with the 


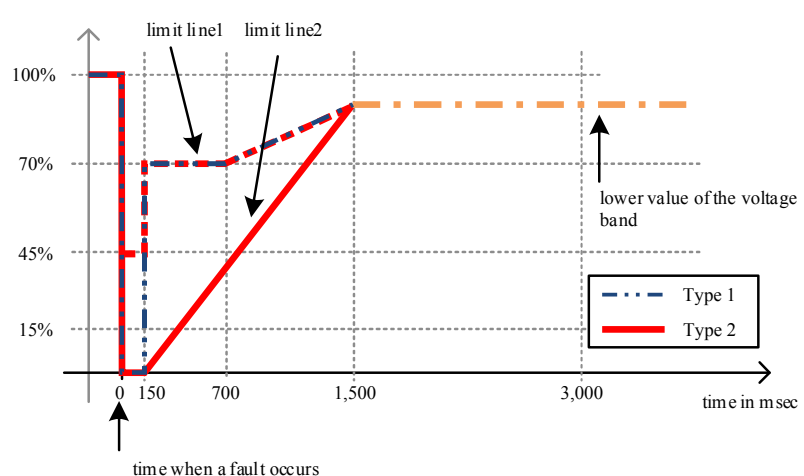

Fig. 4. Limit curves for the voltage pattern at the grid connection for generating plants in the event of a fault in the grid.

H-Bridge and PWM converters. However, the PWM converter can be selectively applied to a controller in order to compensate ripples because dc-link voltage ripple occurs due to non-linear loads. If it is important to reduce the capacity of the capacitor, the ripple compensation controller should be applied. Otherwise, if it is important to reduce the allowable current capacity of the switching element, then the ripple compensation controller is not applied.

This article is organized as follows. The LVRT requirements are described in Section II. In Section III, the PWM method is described, and in Section IV, voltage control for weak-grid generation is explained. In Section $\mathrm{V}$, simulation and experimental results are presented, and some conclusions are given in Section VI.

\section{LVRT CONDITIONS}

The capability of the LVRT is one of the most important issues between the grid codes of countries. The grid codes in renewable systems require that the power converter is not disconnected from the grid in weak grid conditions for a determined time. Grid codes demand the injection of reactive current during a fault in order to maintain the stability of the grid. Fig. 4 shows the voltage pattern of the limit curve (Type 1) when a synchronous generator is directly connected to the grid, and all of the other power system voltage patterns (Type 2) [9], [10]. In Type 1, the generator is directly connected to a grid system in which the upper part of the boundary of Type 1 should be kept connected to the grid. Even if the 3-phase voltages decrease to 0 , which is the earth fault condition, the power converter should be kept connected to the grid. It can contribute to the recovery during $150 \mathrm{~ms}$, and should not cause instability of the power grid.

Type 2 is applied to all of the power generation systems except Type 1. Most of the developed systems for renewable energy sources correspond to Type 2 . In the area of limit line 1, three-phase ground faults and symmetrical grid faults should not cause any instability in the grid. Within this area, all of the power generation system should maintain their connection to the grid. If a generator becomes unstable in

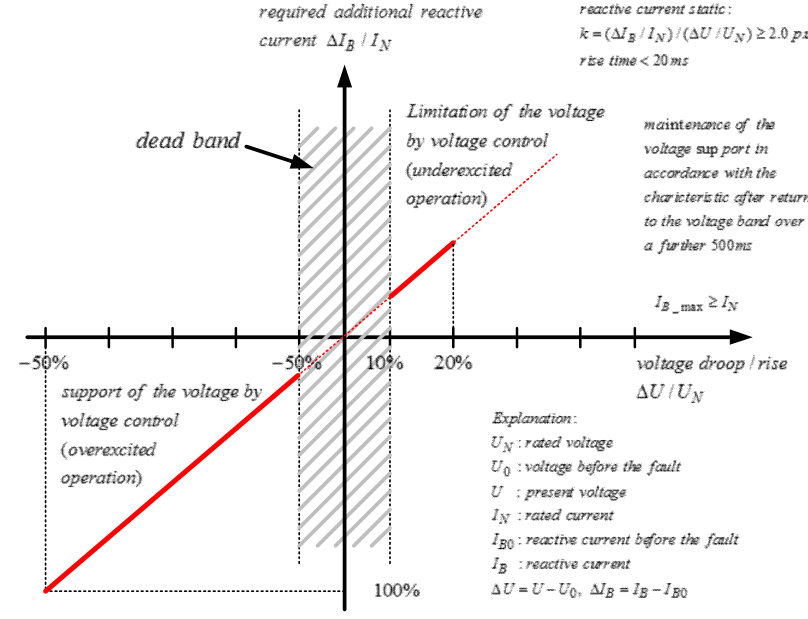

Fig. 5. Reactive current provision requirement when grid fault

grid fault situations, an instantaneous separation is allowed. In addition, all of the systems should be reconnected to the grid within 2 seconds. After re-connecting to the grid, the active power should be supplied by more than $10 \%$ of the rated value per second. In the area under limit line 2 , an instantaneous separation is allowed for all systems. In this region, except for some special occasion, it is possible that the time to reconnect to the grid is 2 seconds or more, and the rate of increase per second of the active power is below $10 \%$ of the rated power. In grid-fault conditions, all of the systems which are not separated from the grid should be supplied with active power instantaneously after restoring the grid fault. In addition, the active power should be increased to the previous value by increasing the rated value by more than $20 \%$ per second.

In the case of a decreased grid voltage, all of the power systems should contribute to the recovery of the grid voltage by supplying reactive current to the grid. According to the rate of decrease in the grid voltage, the conditions of the reactive current supply are shown in Fig. 5. When the rate of change in the grid voltage is within $10 \%$, it is in the normal operating range, where there are no conditions for the reactive current supply. When the rate of change in the grid voltage is more than $10 \%$, two times the reactive current should be supplied to the grid against the voltage regulation. This reactive current should be supplied within $20 \mathrm{~ms}$ after the system fault condition. In addition, when the voltage is recovered to within $10 \%$ of the normal operating range, the reactive current should be supplied to the grid during $500 \mathrm{~ms}$.

\section{PWM METHODS}

The Pulse Width Modulation (PWM) strategy was developed to reduce the total harmonic distortion of output voltage. The carrier-based space vector PWM method has the same properties as the conventional SVPWM with respect to 


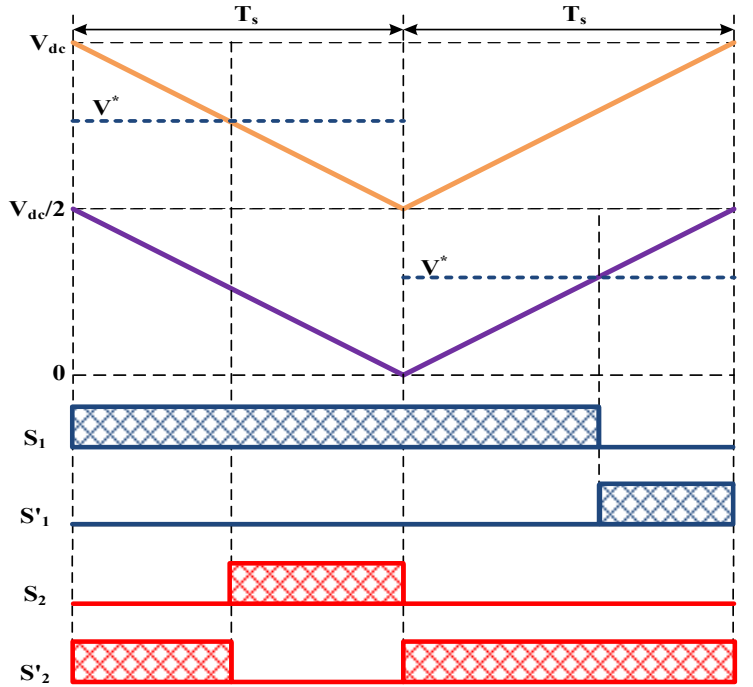

Fig. 6. PWM method of the Phase Disposition carrier-based SVPWM method.

the voltage-second principle. As a result, it is very easy to implement. The space vector PWM method is very difficult to implement because calculating the application time and the re-synthesizing time in order to obtain the gating signal should be determined by sectors. This method requires a lot of computation time. On the other hand, the carrier-based PWM method is widely used in various inverters and multilevel converters because this method makes it easy to obtain the gating signal through comparing the equations of the reference voltage and the phase voltage [11].

\section{A. Phase Disposition PWM Method}

Fig. 6 shows the proposed carrier-based space vector PWM method for diode clamped inverters [12]. This method has an advantage when it comes to expanding simply to higher levels, and maintaining the properties of the SVPWM method based on the principle of the voltage-second balance. The diode-clamped inverter has no leg voltage redundancy, which leads to bad switch utilization. If it is directly applied to cascaded inverters, the switching frequency and the current flowing through the device become different in each unit cell module, which also results in bad switch utilization [13]. In [14], in order to solve this problem, the rotating level-shifted PWM was proposed. However, this method has a disadvantage in that it increases the switching frequency.

\section{B. Phase Shifted PWM Method}

Fig. 7 shows that the phase-shifted (PS) PWM method is the most commonly used modulation technique for cascaded multilevel inverters, because it offers a balanced power distribution among the cell modules and is very easy to implement regardless of the number of cascaded cell modules [15]. In the case of N-levels, this method needs N-1 carriers. However, in the PS PWM method, the status of two of the IGBTs is changed in a switching period so that two voltage

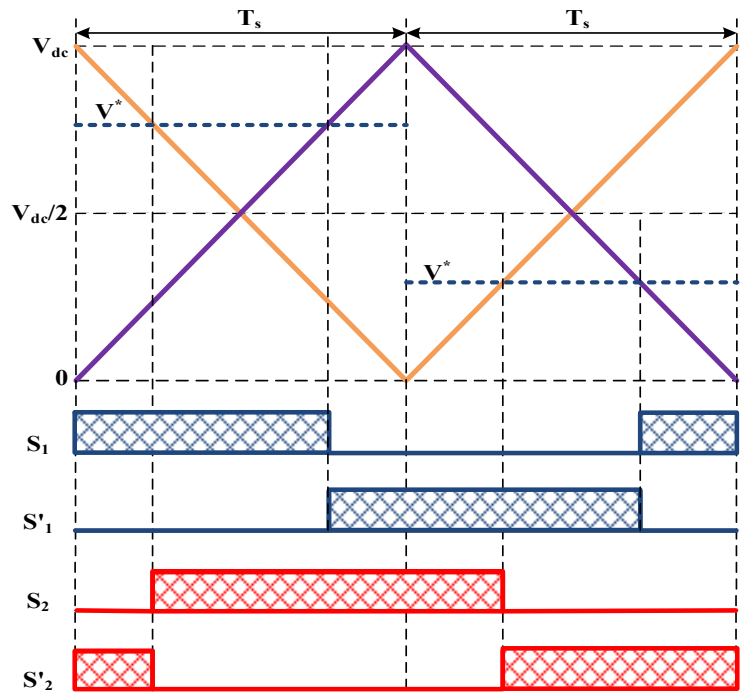

Fig. 7. PWM method of the Phase Shifted carrier-based SVPWM method.

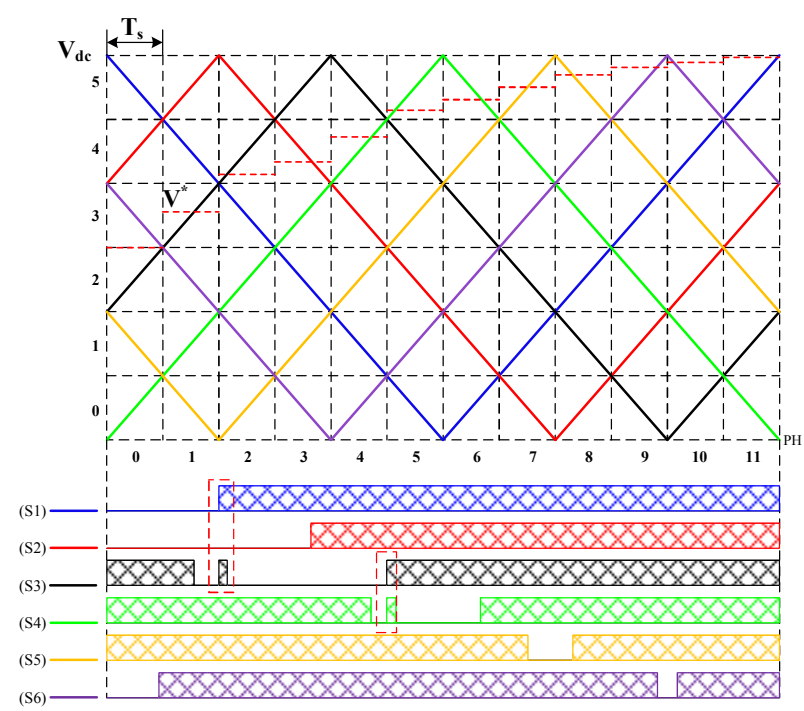

Fig. 8. PS carrier and switching state for 7-level multilevel converter.

levels fluctuate in the synthesized line voltage. Fig. 8 shows the PS carrier and the voltage reference depending on the switching state for the 7-level multilevel converter. A section exists in which the states of two switches are simultaneously changed as shown in Fig. 8. Due to this phenomenon, the PS PWM method has a disadvantage in that the switching loss and the total harmonic distortion of the output voltage are both increased.

\section{Carrier Redistributed PWM Method}

Fig. 9 shows the carriers and each of the switching states of Carrier Redistributed (CR) PWM method according to the voltage reference. In [11], [16], the PWM method has the following features:

1) Carrier-based SVPWM method using adjacent voltage vectors. 


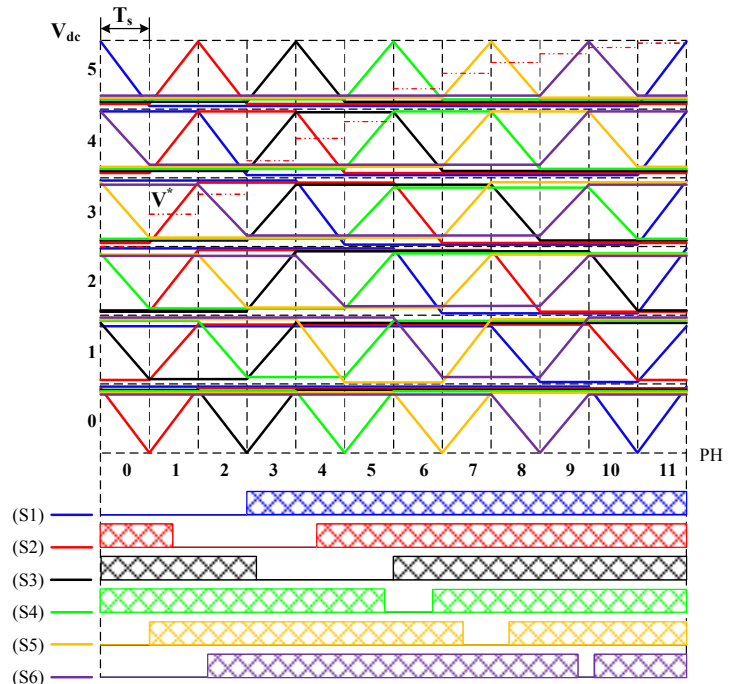

Fig. 9. CR carrier and switching state for 7-level multilevel converter.

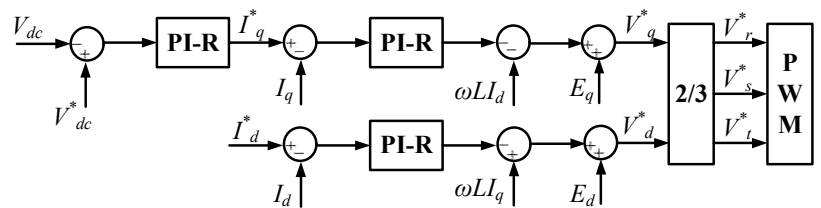

Fig. 10. Block Diagram of DC-Link Ripple Compensator using PIR Controller.

2) Easy expansion to higher levels.

3) Redistribution of the carrier by using leg voltage redundancies.

4) The same utilization for all of the switches at both high and low modulation indices even if the load power factor varies.

5) Even dispersion of the on-off gate pulses for each of the switches.

In a case of N-level multilevel, this carrier-based PWM method requires $(\mathrm{N}-1) 2$ carriers because the number of carrier is increased $(\mathrm{N}-1)$ times more than the PD.

Therefore, it is too difficult to implement with an analog circuit. However, nowadays, it is easy to implement with a digital circuit owing to the development of erasable programmable logic devices (EPLD) and the field programmable gate array (FPGA) technique.

\section{VOLTAGE AND CURRENT CONTROL FOR WEAK GRID GENERATION}

\section{A. Analysis of the DC-Link Voltage Ripple Compensator}

Generally, it is known that if the DC-Link Voltage of the AC-to-DC converter is stably kept constant without a ripple, the capacity of the DC-Link capacitance can be reduced [17]. A ripple which is two times the frequency of the load voltage appears in the DC-Link voltage as (1), when the H-Bridge is connected with a nonlinear load such as a motor.

$$
\begin{gathered}
U_{d c}=\frac{3}{2} V_{q} \frac{I_{q}}{I_{d c}}+\frac{U_{o m} \frac{I_{o m}}{I_{d c}}}{2}\left(\cos \left(2 \omega_{o u t} t\right)\right) \\
P_{d c}=U_{d c} I_{d c}
\end{gathered}
$$

where $I_{q}$ is the active current of the ac-to-dc converter, $\omega_{\text {out }}$ is the angular frequency of the load voltage and the current, while $U_{o m}$ and $I_{o m}$ are the magnitudes of $U_{\text {out }}$ and $I_{\text {out }}$, respectively. $P_{d c}$ is the dc-link power, $U_{d c}$ is the dc-link voltage, and $I_{d c}$ is the dc-link current.

If the DC-Link voltage is kept constant, the Pdc is zero because the DC-Link power flowing into capacitor becomes zero. In (1), the active current reference so that Pdc becomes zero can be derived as (3):

$$
I_{q}^{*}=-\frac{U_{o m} I_{o m}}{3 V_{q}}\left(\cos \left(2 \omega_{\text {out }} t\right)\right)
$$

A typical PI controller cannot compensate for the ripple of the dc-link voltage, because the extracted active power reference becomes a nonlinear function. In [18], two times the frequency of the load voltage was compensated by a PIR controller combined with a PI controller and a resonant controller at both the dc-link voltage controller and the current controller.

Eq. (4) is a transfer function of the PIR controller. Fig. 10 shows a block diagram of the controller.

$$
G_{P I R}(s)=\frac{2 s\left(s K_{P}+K_{I}\right) K_{R}}{s^{3}+s \omega_{r e s}^{2}}
$$

where $\omega_{\text {res }}$ is the resonant frequency of the resonant controller which is equal to two times the load frequency, and $K_{P}, K_{I}$, and $K_{R}$ are the controller gains, respectively.

This controller method is stable when the magnitude of the load current and the frequency become continuous and linear. However, when they are discontinuous and nonlinear, the system can be unstable.

The dual vector current control can be applied in order to improve these drawbacks of the resonant controller. This control method performs the d-q coordinate transformation to be synchronous with $2 \omega_{\text {out }}$, filters the dc component which is shown as $2 \omega_{\text {out }}$ by the $2 \omega_{\text {out }}$ notch filter, and compensates for the dc-link voltage ripple using a PI controller. It is possible to achieve linear-control by using the PI controller. However, this method has disadvantages in that the number of the controller increases two times and that the phase angle with respect to the load voltage should be estimated using the PLL in the ac-to-dc converter.

When the dc-link voltage ripple is compensated, the total harmonic distortion of the output voltage and the current can be improved because the output voltage of the H-Bridge is generated by using the dc-link voltage. In addition, the capacity of the dc-link capacitance can be reduced because the dc-link voltage is controlled constantly. However, in order to compensate for the dc-link voltage ripple in the 


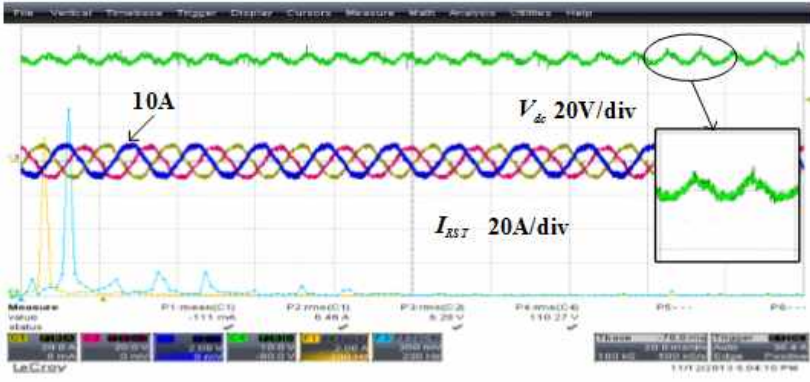

(a)

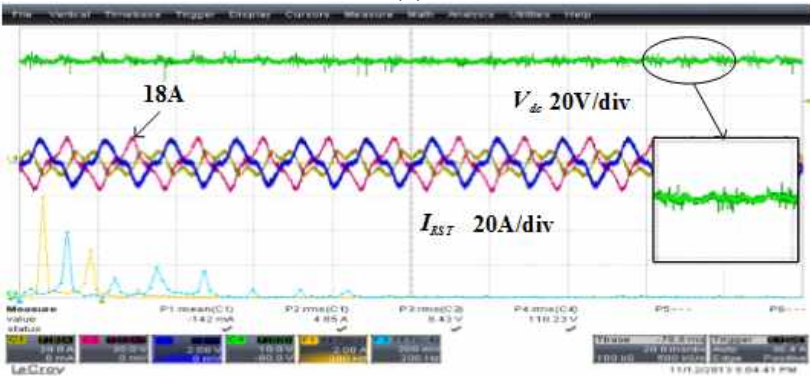

(b)

Fig. 11. (a) DC-link voltage and grid-side current without DC-link ripple compensation. (b) DC-link voltage and grid-side current with DC-link ripple compensation.

ac-to-dc converter, the grid side input current appears to be $3 \omega_{\text {out }}$ as in (7) through injecting $2 \omega_{\text {out }}$ into the d-q current.

Fig. 11(b) shows that the ripple of the input current from the grid side is increased proportional to the load power so that a switching device with an increased current capacity should be selected. Therefore, when it is important to reduce the capacity of the capacitor, a ripple compensator should be applied. However, when it is important to reduce the current capacity of the switching device, a ripple compensator is not applied.

$$
\begin{gathered}
{\left[\begin{array}{l}
I_{\alpha} \\
I_{\beta}
\end{array}\right]=\left[\begin{array}{cc}
\cos (\omega t) & -\sin (\omega t) \\
\sin (\omega t) & \cos (\omega t)
\end{array}\right]\left[\begin{array}{l}
0 \\
-\frac{U_{o m} I_{o m}}{3 V_{q}}(\cos (2 \omega t))
\end{array}\right]} \\
I_{\alpha}=\frac{U_{o m} I_{o m}}{6 V_{q}}(\sin (3 \omega t)-\sin (\omega t)) \\
I_{\beta}=-\frac{U_{o m} I_{o m}}{6 V_{q}}(\cos (3 \omega t)+\cos (\omega t)) \\
{\left[\begin{array}{l}
I_{r} \\
I_{s} \\
I_{t}
\end{array}\right]=\left[\begin{array}{cc}
1 & 0 \\
-1 / 2 & 1 / 2 \\
-1 / 2 & -1 / 2
\end{array}\right]\left[\begin{array}{l}
\frac{U_{o m} I_{o m}}{6 V_{q}}(\sin (3 \omega t)-\sin (\omega t)) \\
-\frac{U_{o m} I_{o m}}{6 V_{q}}(\cos (3 \omega t)+\cos (\omega t))
\end{array}\right]}
\end{gathered}
$$

\section{B. Weak Grid Generation Independent Voltage Controller}

The weak grid of a 3-phase system can be typically classified into balanced conditions and unbalanced conditions. In order to generate the 3-phase balanced conditions of the weak grid, the active voltage can be controlled in the d-q rotational reference frame. However, the weak grid of the
TABLE I

SiMULATION CONFIGURATIONS

\begin{tabular}{cc}
\hline Parameters & value \\
\hline DC Capacitance $\left(C_{d c}\right)$ & $3300[\mathrm{uF}]$ \\
Boost Inductance $\left(L_{g}\right)$ & $1[\mathrm{mH}]$ \\
Cell DC-Link & $110[\mathrm{~V}]$ \\
Voltage $\left(U_{d c}\right)$ & \\
Total DC-Link & $660[\mathrm{~V}]$ \\
Voltage $\left(U_{d c_{-} \text {total }}\right)$ & \\
Generated Voltage & $60[\mathrm{~Hz}]$ \\
Frequency & \\
Generated Voltage $\left(U_{\text {out }}\right)$ & $380[\mathrm{~V}]$ \\
Generated Voltage MI & $0 . \quad 8135$ \\
PD Carrier Period & $400 \mathrm{usec}$ \\
PS Carrier Period & $2400 \mathrm{usec}$ \\
CR Carrier Period & $400 \mathrm{usec}$ \\
\hline
\end{tabular}

unbalanced conditions requires a 3-phase independent controller. Fig. 12 shows a block diagram of a controller generating the weak grid under the unbalanced conditions. The phase angle about each phase is estimated by using a PLL with respect to the 3-phase voltage. Each 3-phase voltage and current is transformed into the $\alpha-\beta$ stationary reference frame using an all-pass filter with a 90 degree phase delay. Eq. (8) is the transfer function of the all-pass filter. The $\mathrm{d}$-q coordinate transformation is performed by the estimated phase angle with respect to each phase. After that, the independent phase controller is applied with respect to each phase using the transformed signal.

$$
\begin{array}{r}
H_{\text {allpass }}(s)=\frac{s-a}{s+a} \\
R C=\frac{-\cos \left(\theta_{\text {delay }} / 2\right)}{\omega_{\text {out }}}
\end{array}
$$

where $a$ is $1 /(2 \pi R C)$, and $\theta_{\text {delay }}$ is the phase delay angle.

A conventional 3-phase d-q controller cannot control each phase independently. However, the proposed controller in this study is suitable for a VSE because it can control the voltage and current of each phase.

\section{SIMULATION AND EXPERIMENTAL RESULTS}

Comparisons of the PWM methods and the proposed control method have been verified by simulation and experimental results. Table I shows the simulation configuration.

Fig. 13(A) shows the leg cell modules according to the output line-to-line voltage and the output voltage modulation indices, when phase disposition PWM method is applied. This PWM method is shown to produce an uneven distribution of power among the cells due to unbalanced switching. In the case of a low modulation index, it can be 


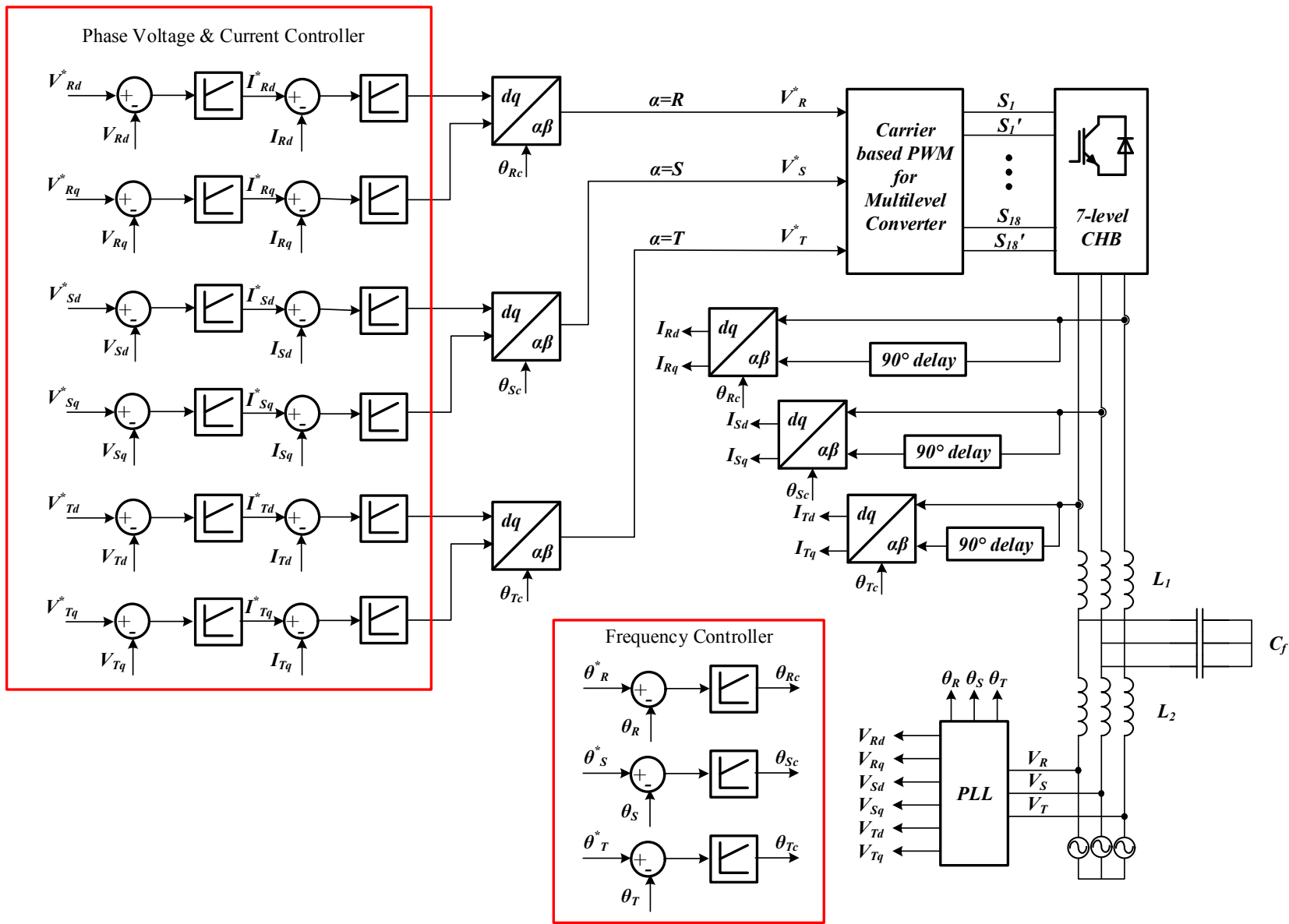

Fig. 12. 3-phase independent controller of the weak grid generator.

confirmed that only a specific cell module operates. Fig. 13(B) shows the output line-to-line voltage and the output voltage of the leg cell modules according to the modulation indices, when the phase shifted PWM method is applied. This PWM method produces an even distribution of power among the cells due to the balanced switching of each cell module in the leg. However, there is a section in which two voltage levels change. As a result, the switching loss is increased and the total harmonic distortion becomes poor. Fig. 13(C) shows the voltage of the leg modules according to the line-to-line voltage and the modulation indices, when the Carrier Redistributed PWM method is applied. In the CR PWM method, the power is produced and evenly distributed among the cells just as in the PS PWM, and it maintains the characteristics of the PD PWM. From the comparison of the three PWM methods, it can be confirmed that the CR PWM method has the best characteristics.

Fig. 14 shows that it performed boosting at 1 second, and that it performed H-Bridge PWM at 1.5 second. The dc-link voltage ripple was compensated by the enabled controller at 2.5 second.

Fig. 15 shows the waveform for generating the weak grid. The grid voltage was gradually increased from 1.5 second, and the weak grid voltage was generated from 2.7 second. Fig. 15(a) shows a type-1 limit line 1, Fig. 15(b) shows a type-2 limit line 1, and Fig. 15(c) shows a type-2 limit line 2.

Voltage source equipment is composed of 7-level cascaded $\mathrm{H}$-Bridge converters, and the unit cell module is composed of a PWM converter and an H-Bridge. Each cell module has a slave controller in it and the VSE has a master controller that serves as the host controller. The Slave controller has the role of controlling the cell module, and the master controller has the role of controlling the output voltage and the current. The Slave control board and the Master control board are composed of TMS320F28335s, while CAN communication is adopted for communication among the control boards. In addition, the cables which are related to the communication and the PWM are used with optical cables. In order to implement various multilevel PWM methods, the PWM board was configured using an erasable programmable logic device. Fig. 16 shows the leg cell modules of the VSE and a picture of the master control board and the PWM board. Fig. 17 shows the configuration of the communication system and the definition of the data frame. If a node is connected at the CAN bus, the other node is on standby until the CAN bus becomes unoccupied. This is due to the fact that the CAN communication shares the communication bus. Thus, in order to avoid a collision when several nodes are simultaneously 

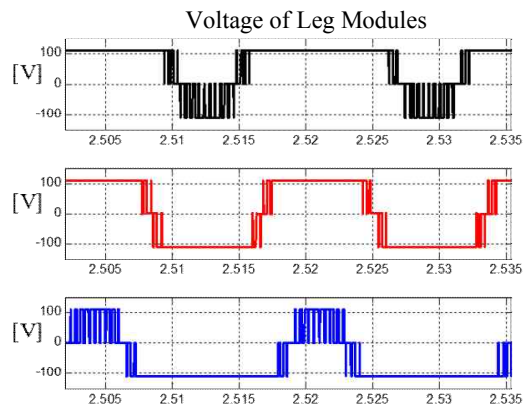

(a)

Modulation Index: 0.81
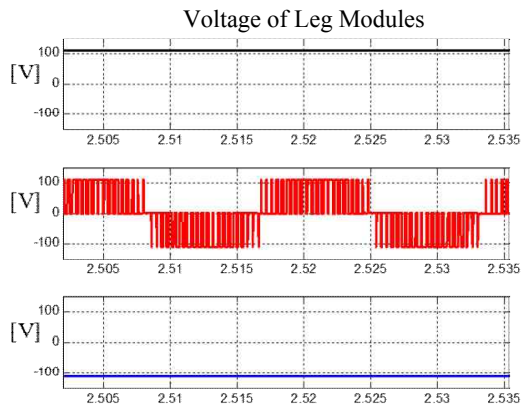

(b) Modulation Index: $\mathbf{0 . 2}$

Line-to-Line Voltage

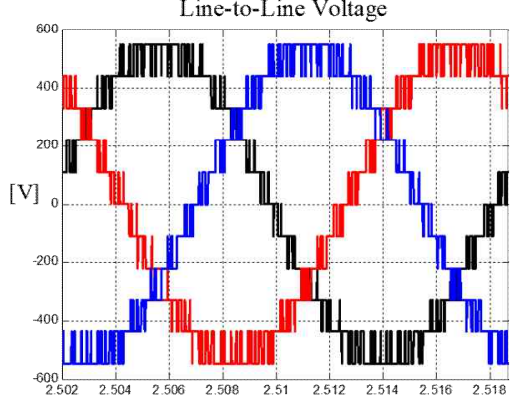

(c) Line-to-Line PWM Voltage

(A) Phase Disposition PWM
Voltage of Leg Modules
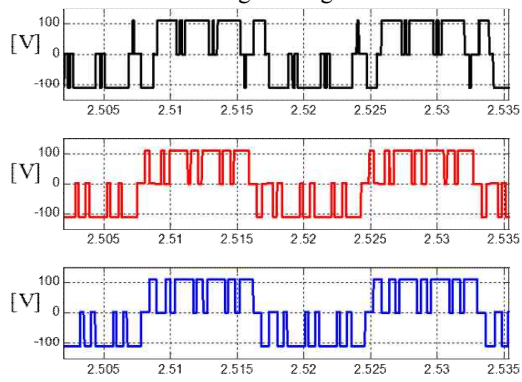

(a)

Modulation Index: 0.81

Voltage of Leg Modules
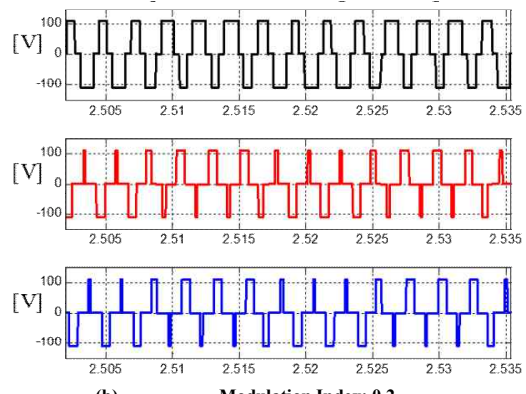

(b) Modulation Index: 0.2

Line-to-Line Voltage

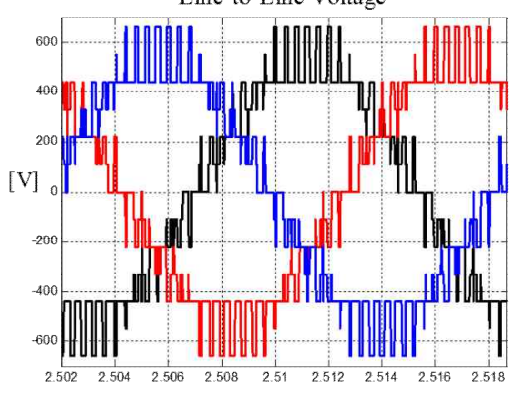

(c)
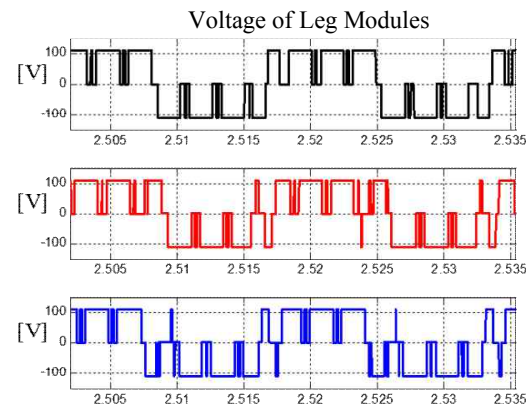

(a) Modulation Index: 0.81 Voltage of Leg Modules
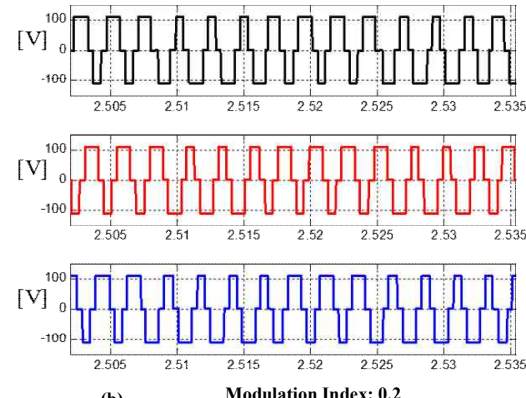

Modulation Index: $\mathbf{0 . 2}$

Line-to-Line Voltage

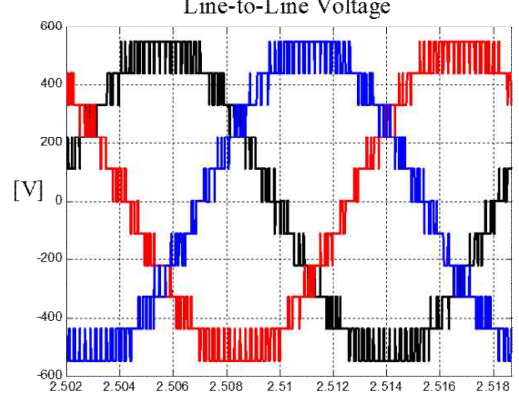

(c) Line-to-Line PWM Voltage

(C) Carrier Redistributed PWM

Fig. 13. (a) Voltage of leg modules at $\mathrm{MI}=0.81$. (b) Voltage of leg cell modules at MI=0.2. (c) Line-to-line PWM Voltage. (A) Phase Disposition PWM Method. (B) Phase Shifted PWM Method. (C) Carrier Redistributed PWM Method.

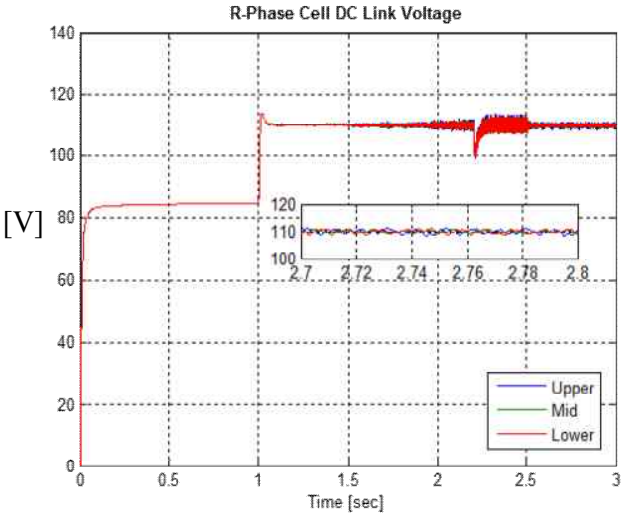

Fig. 14. (a) DC-link voltage and grid-side current without DC-link ripple compensation. (b) DC-link voltage and grid-side current with DC-link ripple compensation.

connected at the CAN bus, the nodes are prioritized and then communicated. However, if a high priority node is sustainably connected at the bus, the other node cannot be connected at the bus. Therefore, in order to be connected as equally as possible, all of the nodes are time-scheduled. Fig. 18 shows a time scheduling diagram for the VSE in order to connect as equally as possible. Fig. 19 shows the waveform of the experiment with the carrier redistributed PWM and the phase shifted PWM. Fig. 20 shows the waveform of the experiment with the weak grid generation controller. Fig. 20(a) shows the waveform which performs the $\alpha-\beta$ transformation using an all-pass filter, Fig. 20(b) shows the waveform which performs the d-q transformation using Fig. 20(a), and Fig. 20(c) is a waveform diagram estimating the phase angle. In addition, Fig. 20(d) is a waveform which generates the weak grid controlling the phase voltage. The total harmonic distortion of the output voltage and the current were measured under various load resistor conditions combined with voltage source equipment that is adjusted from $5 \mathrm{~kW}$ up to $20 \mathrm{~kW}$. At this time, the total harmonic 

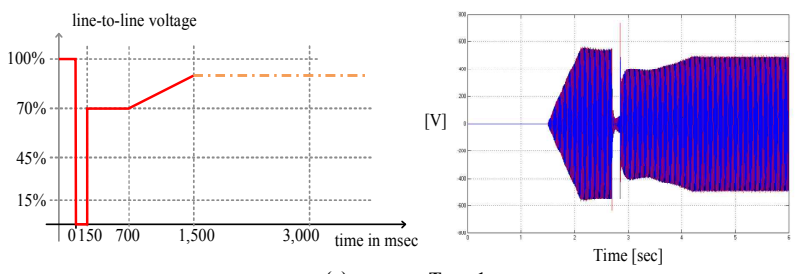

Type 1

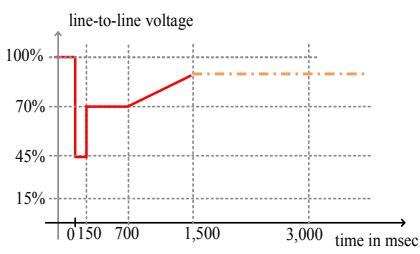

(b) Type 2, Limit line 1
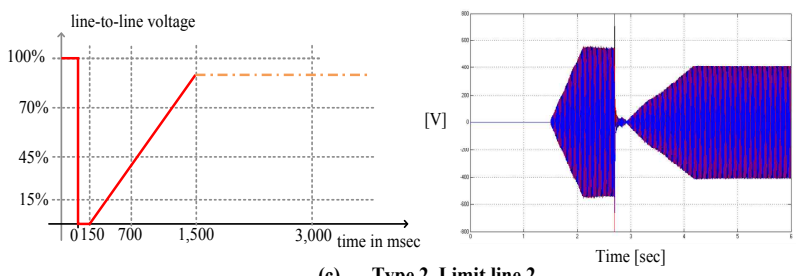

(c) Type 2, Limit line 2

Fig. 15. Weak grid voltage generated waveform. (a) Grid code type 1. (b) Grid code type 2-limit line 1. (c) Grid code type 2-limit line 2.

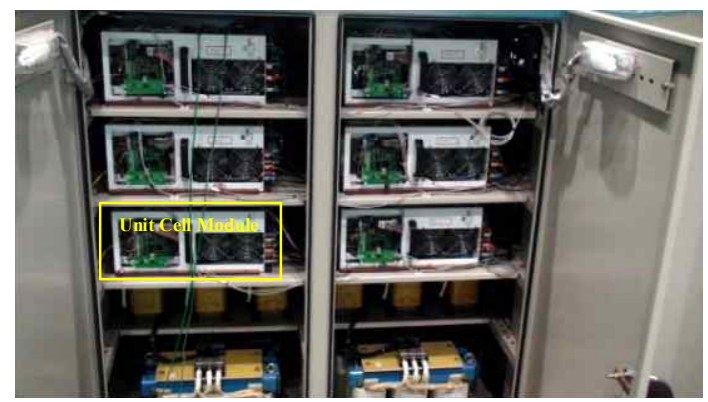

(a)

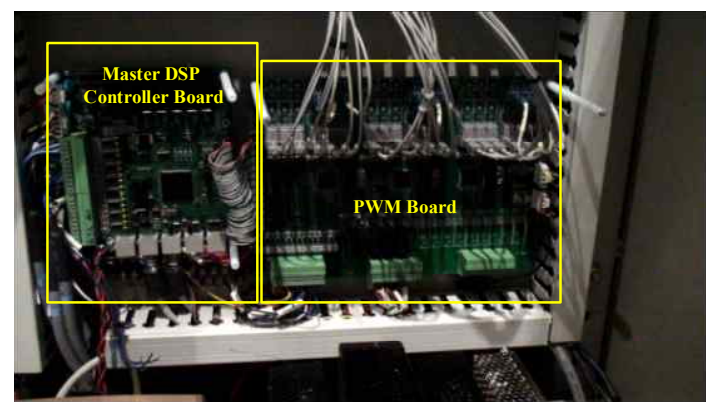

(b)

Fig. 16. (a) The leg cell modules of voltage source equipment, (b) Master Control Board \& PWM Board.

distortion is measured by an N4L precision power analyzer using the difference THD mode of (10). These measurements show that the CR PWM methods are excellent both in terms of the output voltage and the current as shown in Fig. 21. Fig. 22 shows the waveform of the experiment on the dc-link voltage which performs boosting to $640 \mathrm{~V}$ by combining the

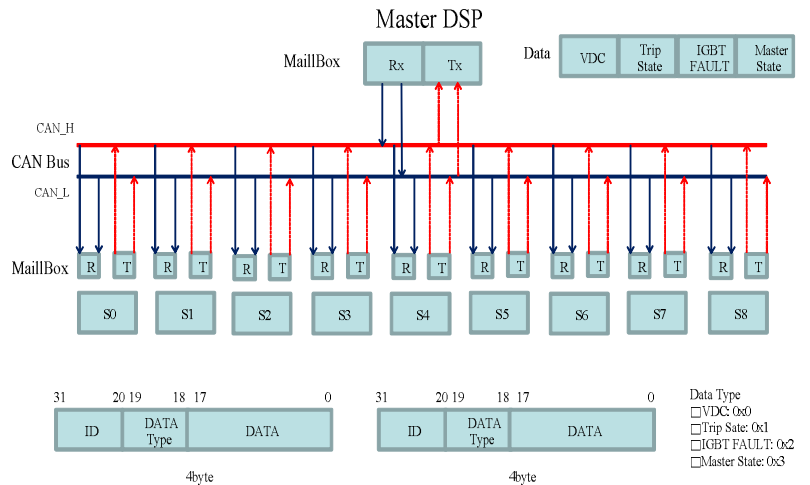

Fig. 17. Structure of communication system \& definition of can data frame.

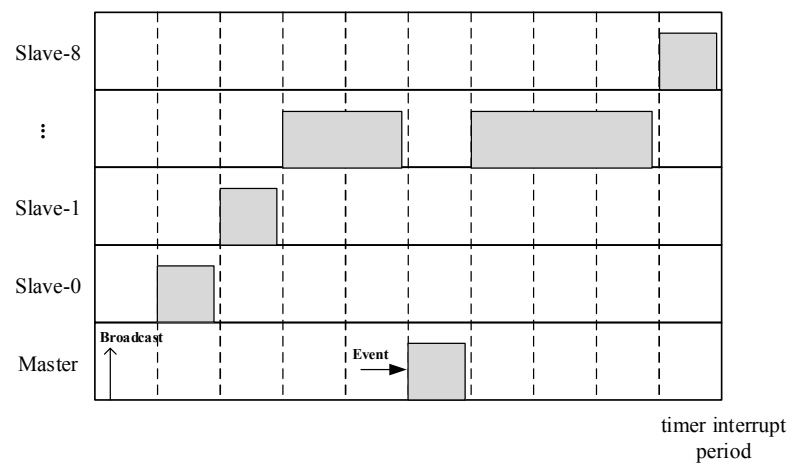

Fig. 18. The time scheduling diagram.

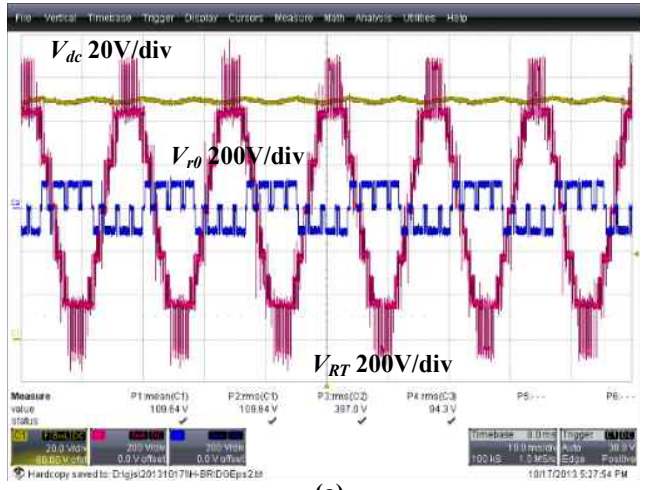

(a)

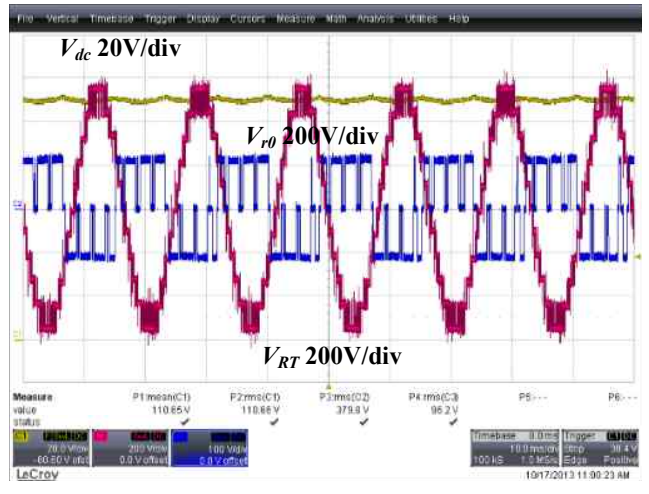

(b)

Fig. 19. DC-Link Voltage, unit cell output voltage, and line-to-line output voltage, (a) Phase Shifted PWM Method, (b) Carrier Redistributed PWM Method. 


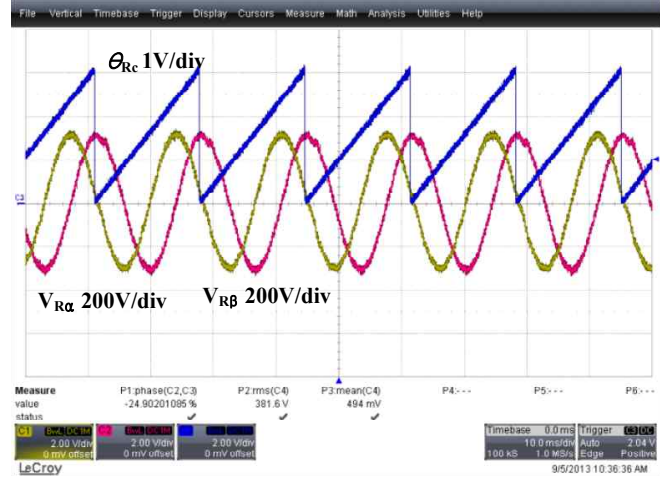

(a)

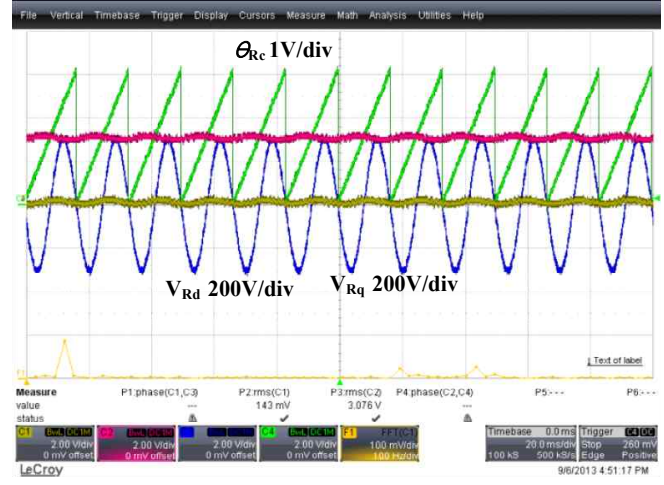

(b)

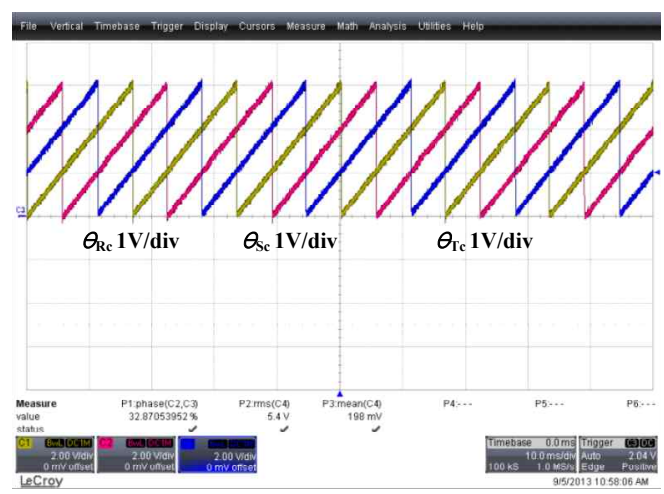

(c)

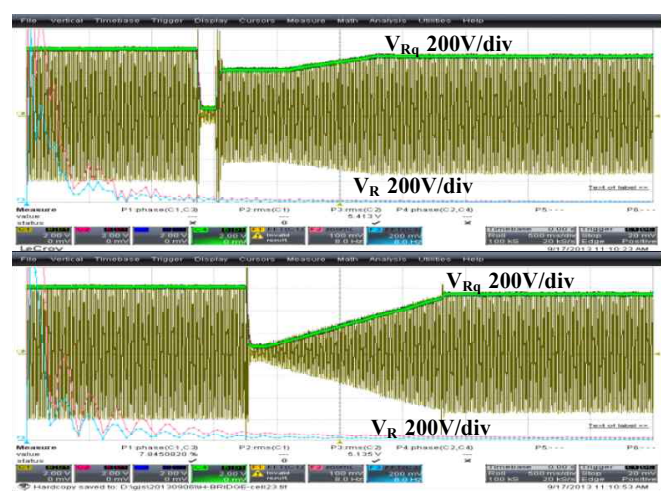

(d)

Fig. 20. Weak grid generation controller experiment waveform, (a) single phase $\alpha-\beta$ transformation. (b) Single phase d-q transformation. (c) Estimated phase theta. (d) Generated weak grid voltage.
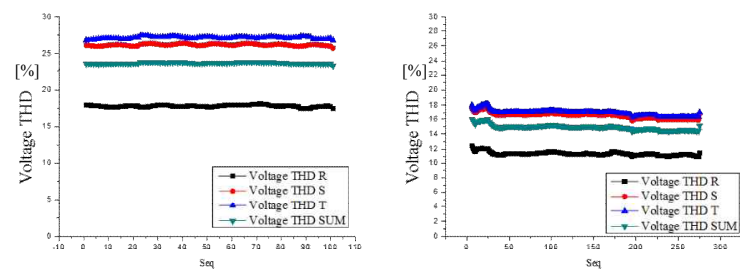

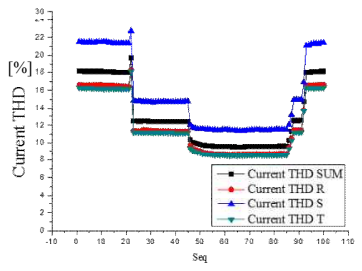

(a)

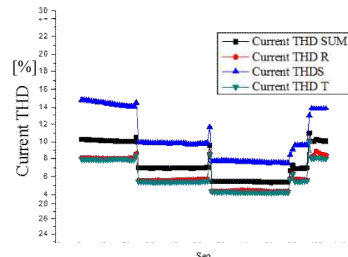

(b)
Fig. 21. Output PWM voltage and current total harmonic distortion. (a) Phase shifted PWM method. (b) Carrier redistributed PWM method.

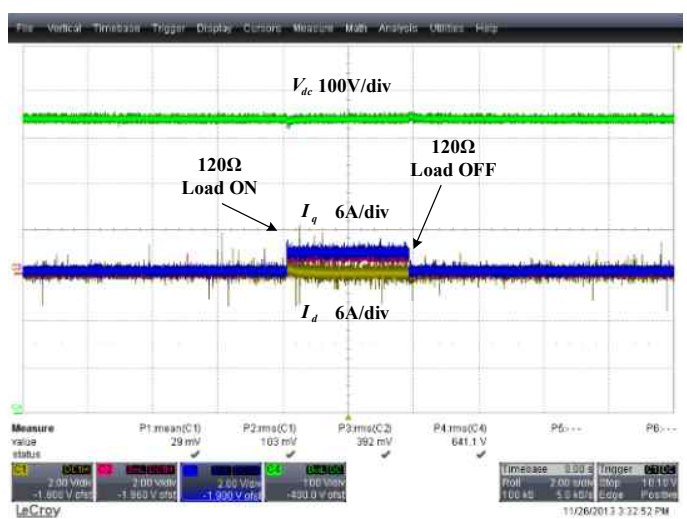

Fig. 22. The boosting waveform of grid-side converter combination with voltage source equipment.

grid-side converter with the voltage source equipment.

$$
T H D=\frac{\sqrt{r m s^{2}-h_{1}^{2}}}{h_{1}}
$$

\section{CONCLUSIONS}

This paper proposed voltage source equipment and a weak grid generation controller using 7 level cascaded H-Bridge converters. In addition, three different PWM methods for multi-level converters were analyzed and compared. The proposed structure of the VSE is easy to expand for large capacity, and it can generate various grid fault voltages. As a result of comparing the PWM methods for a multi-level converter, the PD method has been shown to have excellent performance with a high quality of the output voltage and current. However, the generated electric power is not uniformly distributed to all of the cells, so it is not appropriate to apply. On the other hand, the active power of the PS method is uniformly distributed. However, since the switching state is changed into the two statuses, the switching loss increases and the output voltage and current quality are 
relatively poor. Meanwhile, it is confirmed that the $\mathrm{CR}$ method is the best method among the three PWM methods because the quality of the voltage and current is excellent and the active power is uniformly distributed as demonstrated in section $\mathrm{V}$. The proposed weak grid generation controller makes a variety of grid faults with an independent controller phase state.

\section{REFERENCES}

[1] The Global Wind Energy Council, May 2013[Online], Available: http://www.gwec.net/.

[2] H. Shin, H. S. Jung, and S. K. Sul, "Low voltage ride through(LVRT) control strategy of grid-connected variable speed wind turbine generator system," Power Electronics and ECCE Asia(ICPE \& ECCE), 2011 IEEE 8th International Conference on, pp. 96-101, 2011.

[3] S. M. Muyeen, R. Takahashi, T. Murata, and J. Tamura, "A variable speed wind turbine control strategy to meet wind farm grid code requirements," IEEE Trans. Power Syst., Vol. 25, No. 1, pp.331-340, Feb. 2010.

[4] M. Garcia-Gracia, M. P. Comech, J. Sallan, D. Lopez-Andia, and O. Aloneso, "Voltage dip generator for wind energy system up to 5MW," Applied Energy, Vol. 86, No. 4, pp. 565-574, Apr. 2009.

[5] C. Wessels, R. Lohde, and F. W. Fuchs, "Transformer based voltage sag generator to perform LVRT and HVRT tests in the laboratory," Power Electronics and Motion Control Conference (EPE/PEMC), $2010 \quad 14$ th International, pp. T11-8-T11-13, 2010.

[6] C. Saniter and J. Janning, "Test bench for grid code simulations for Multi-MW wind turbines, design and control," IEEE Trans. Power Electron., Vol. 23, No. 4, pp. 1707,1715, Jul. 2008.

[7] NREL, June 2013[Online], Available: http://www.nrel.gov/electricity/transmission/pdfs/58761.p df.

[8] J. Wu, M. Dong, D. Xu, and G. Duan, "Study on power grid fault simulation device based on foreback control," Electrical and Control Engineering(ICECE), International Conference on, pp.407-410, 2011.

[9] E. ON Netz. Grid Code. High and extra high voltage. Bayreuth, 1st April 2006.

[10] E. ON Netz. Requirements for Offshore Grid Connections in the E. ON Netz Network. 1st April 2008.

[11] D. W. Kang, Y. H. Lee, B. S. Suh, C. H. Choi, and D. S. Hyun, "An improved carrier-based SVPWM Method Using Leg Voltage Redundancies in Generalized cascaded multilevel inverter topology," IEEE Trans. Power Electron., Vol. 18, No. 1, pp. 180-187, Jan 2003.

[12] Y. H. Lee, R. Y. Kim, and D. S. Hyun, "A novel SVPWM strategy considering DC-Link balancing for a multi-level voltage source inverter," in Proc. APEC'99 Conf., pp. 509-514, Vol. 1, 1999.

[13] M. Malinowski, K. Gopakumar, J. Rodriguez, and M. A. Perez, "A survey on cascaded multilevel inverters," IEEE Trans. Ind. Electron., Vol. 57, No. 7, pp. 2197-2206, Jul. 2010.

[14] D. Sreenivasarao, P. Agarwal, and B. Das, "Performance evaluation of carrier rotation strategy in level-shifted pulse-width modulation technique," IET Power Electronics, Vol. 7, No. 3, pp. 667-680, Mar. 2014.

[15] R. Gupta, A. Ghosh, and A. Joshi, "Switching characterization of cascaded multilevel-inverter-controller systems," IEEE Trans. Ind. Electron., Vol. 55, No. 3, pp. 1047-1058, Mar. 2008.

[16] D. W. Kang, B. K. Lee, J. H. Jeon, T. J. Kim, and D. S. Hyun, "A symmetric carrier technique of CRPWM for voltage balance method of flying-capacitor multilevel inverter," IEEE Trans. Ind. Electron., Vol. 52, No. 3, pp. 879-888, Jun. 2005.

[17] W. J. Lee and S. K. Sul, "DC-link voltage stabilization for reduced DC-link capacitor inverter," IEEE Trans. Ind. Appl., Vol. 50, No. 1, pp. 404-414, Jan./Feb. 2014.

[18] Y. Xibo, "Multilevel modular high power converters for 10MW wind turbines," Industrial Electronics (ISIE), 2013 IEEE International Symposium on, pp. 1-7, 2013.

[19] K. Arun and K. Selvajyothi, "Observer based current controlled single phase grid connected inverter," Procedia Enginerring, Vol. 64, pp. 367-376, Sep. 2013.

[20] S. P. Gawande and M. R. Ramteke, "Current controlled PWM for multilevel voltage-source inverters with variable and constant switching frequency regulation techniques: A review," Journal of Power Electronics, Vol. 14, No. 2, pp. 302-314, Mar. 2014.

[21] T. H. Nguyen and D. C. Lee, "Improved LVRT capability and power smoothening of DFIG wind turbine systems," Journal of Power Electronics, Vol. 11, No. 4, pp. 568-575, Jul. 2011.

[22] S. P. Gawande and M. R. Ramteke, "Current controlled PWM for multilevel voltage-source inverters with variable and constant switching frequency regulation techniques: A review," Journal of Power Electronics, Vol. 14, No. 2, pp. 302-314, Mar. 2014.

[23] N. H. Q. Thinh and W. H. Kim, "Implementation of fuzzy self-tuning PID and feed-forward design for high-performance motion control system," International Journal of Fuzzy Logic and Intelligent Systems, Vol. 14, No. 2, pp. 136-144, Jun. 2014.

[24] G. K. Kasal and B. Singh, "H-bridge VSC with a T-connected transformer for a 3-phase 4-wire voltage and frequency controller of an isolated asynchronous generator," Journal of Power Electronics, Vol. 9, No. 1, pp. 43-50, Jan. 2009.

[25] H. M. Pirouz and M. T. Bina, "Modular multilevel converter based STATCOM topology suitable for medium-voltage unbalanced systems," Journal of Power Electronics, Vol. 10, No. 5, pp. 572-578, Sep. 2010.

[26] G. B. Chung, "Takagi-Sugeno fuzzy integral control for asymmetric half-bridge DC/DC converter," International Journal of Fuzzy Logic and Intelligent Systems, Vol. 7, No. 1, pp. 77-74, Mar. 2007.

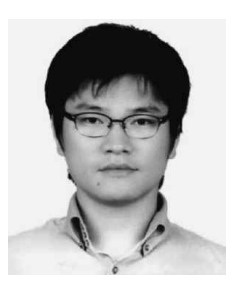

Jin-Su Gwon (S'13) was born in Masan, Korea, in February 1983. He received his B.S. and M.S. degrees in Information and Communication Engineering from Kyungnam University, Masan, Korea, in 2009 and 2011, respectively. He is currently pursuing his $\mathrm{Ph} . \mathrm{D}$. degree in Electrical Engineering at Pusan National University, Busan, Korea. Since 2009, he has been with the Korea Electrotechnology Research Institute (KERI), Changwon, Korea. His current research interests include the control of HVDCs, multilevel converters, and renewable energy. 


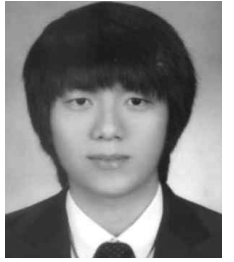

Chun-Sung Kim (S'13) was born in Gwangju, Korea, on August 22, 1982. He received his M.S. degree in Electrical Engineering from Chonnam National University, Gwangju, Korea, in 2011, where he is currently pursuing his $\mathrm{Ph} . \mathrm{D}$. degree. $\mathrm{He}$ has been with the Korea Electrotechnology Research Institute (KERI), Changwon, Korea, since 2012. His current research interests include the control of HVDCs, wind energy generation, and the application of power electronics to power systems.

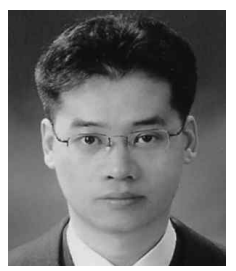

Dae-Wook Kang (S'99-M'04) received his B.S., M.S., and Ph.D. degrees in Electrical Engineering from Hanyang University, Seoul, Korea, in 1998, 2000, and 2004, respectively. Since 2004, he has been a Senior Researcher with the Korea Electrotechnology Research Institute (KERI), Changwon, Korea. His current research interests include the control of HVDCs, multilevel converters, renewable energy, and the application of power electronics to power systems.

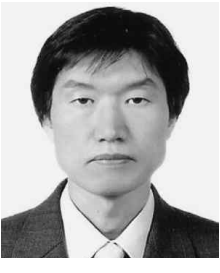

Jung-Woo Park was born in Chungnam, Korea, in February 1963. He received his B.S and M.S. degrees in Electronic Engineering from Chungnam National University, Daejeon, Korea, in 1986 and 1988, respectively. He received his Ph.D. degree in Electrical Engineering from Kyungpook National University, Daegu, Korea. Since 1998, he has been a Principal Researcher with the Korea Electrotechnology Research Institute (KERI), Changwon, Korea. His current research interests include the control of HVDCs, multilevel converters, wind energy generation, and renewable energy.

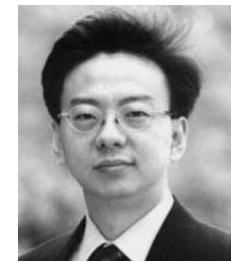

Sungshin Kim (M'97) received his B.S. and M.S. degrees in Electrical Engineering from Yonsei University, Seoul, Korea, in 1984 and 1986, respectively. He received his Ph.D. degree in Electrical and Computer Engineering from the Georgia Institute of Technology, Atlanta, GA, USA, in 1996. He is currently a Professor in the School of Electrical Engineering, Pusan National University, Busan, Korea. His current research interests include intelligent control, intelligent robots, hierarchical learning structures, and fault diagnosis and prognosis. 